\title{
Temporal and spatial evolution patterns and prediction of drought in China in recent 500 years
}

\section{Bing Guo ( $\nabla$ guobingjl@163.com )}

Shandong University of Technology,school of civil architectural engineering

\section{Rui Zhang}

Aerospace Information Research Institute, Chinese Academy of Sciences

\section{Wenqian Zang}

Aerospace Information Research Institute, Chinese Academy of Sciences

\section{Yuefeng Lu}

School of Civil Architectural Engineering, Shandong University of Technology

\section{Chao Meng}

Key Laboratory of Land use, MNR, China Land Survey and Planning Institute

\section{Dafu Zhang}

School of Civil Architectural Engineering, Shandong University of Technology

Xiaoyan Zhen

Key Laboratory of Meteorology and Ecological Environment of Hebei Province

\section{Research Article}

Keywords: Drought, Gravity model, Temporal and spatial evolution, Prediction

Posted Date: February 22nd, 2021

DOl: https://doi.org/10.21203/rs.3.rs-212805/v1

License: (c) (1) This work is licensed under a Creative Commons Attribution 4.0 International License.

Read Full License 
1 Temporal and spatial evolution patterns and prediction of

2 drought in China in recent 500 years

3

4

5

6

7

Bing Guo ${ }^{1,2,4,5,6,7,8,9^{*}}$, Rui Zhang ${ }^{8, *}$, Wenqian Zang ${ }^{8, *}$, Yuefeng $\mathrm{Lu}^{2}$,Chao Meng ${ }^{5}$, Dafu Zhang $^{2}$,Xiaoyan Zhen ${ }^{9}$

${ }^{1}$ Geomatics Technology and Application key Laborlatory of Qinghai Province, Xining 810001, China;

${ }^{2}$ School of Civil Architectural Engineering, Shandong University of Technology, Zibo 255000, Shandong, China;

${ }^{3}$ State Key Laboratory of Resources and Environmental Information System, Institute of Geographic Sciences and Natural Resources Research of Chinese Academy of Sciences, Beijing 100101, China;

${ }^{4}$ Key Laboratory of National Geographic Census and Monitoring, Ministry of Natural Resources, Wuhan 430072, China;

${ }^{5}$ Key Laboratory of Land use, MNR, China Land Survey and Planning Institute, Beijing, 100035, China;

${ }^{6}$ Key Laboratory for Digital Land and Resources of Jiangxi Province, East China University of Technology, Nanchang 330013, China;

${ }^{7}$ MOE Key Laboratory of Western China's Environmental System , Lanzhou University, Lanzhou 730000, Gansu, China;

${ }^{8}$ Aerospace Information Research Institute, Chinese Academy of Sciences, 100101, Beijing, China;

${ }^{9}$ Key Laboratory of Meteorology and Ecological Environment of Hebei Province, Shijiazhuang 
050021, Hebei, China;

\section{*Corresponding Author E-mail:}

Email:guobingj1@163.com;zangwq@radi.ac.cn

Abstract: Drought is a prominent disaster in Chinese history. Analysing the spatial and temporal evolution laws of drought could provide decision supports for drought prevention and control. However, fewer studies were applied to investigate the long-term evolution rules of drought events on different spatial and temporal scales. In this paper, the spatio-temporal changes patterns of drought in China were analysed with geostatistical methods based on the 1470-2000a drought datasets in China, and then the possible future drought trend was predicted. Results showed that :(1) The drought risk in the northern region was the highest during the past 500 years. And, the drought intensity index showed an overall increasing trend with detail pattern of weakening->strengthening-> weakening-> strengthening; (2) The drought condition in the north was server than that in the south, but the drought trend in the south was significantly aggravated. (3) The drought gravity centres were mainly distributed in the north, but it showed a tendency to move southward. (4) From 1470 to 2000, the study area showed a significant drought enhancements, which was predicted to show an increasing trend of drought after 2000.

Keywords: Drought; Gravity model; Temporal and spatial evolution; Prediction

\section{Introduction}

The fifth assessment report of the Intergovernmental Panel on climate change (IPCC) pointed out that under the stress of global warming, the frequency and intensity of extreme weather and climate events, such as drought and extreme high 
temperature, are increasing in the global scope (Bai et al, 2020; Guo et al.,2020c). In recent 50 years, the annual average surface temperature warming in China is about $1.1^{\circ} \mathrm{C}$, and the warming rate is close to $0.22^{\circ} \mathrm{C} /(10 \mathrm{a})$, which is significantly higher than the global or hemispherical average warming rate in the same period (Ren et al., 2005; Shi,2011; Guo et al., 2020d). Drought is the most prominent environmental problem in northern China, while that of southern and eastern parts is also aggravating (Shi, 2009; Liu et al., 2012; Chen et al.,2013; Hu et al., 2015). Revealing the spatial and temporal change rules can provide important decision supports for the drought prevention and control (Xu et al., 2015; Sergio et al., 2020). However, most previous studies were applied to investigate evolution rules of drought in short period or small time scale. The large time scale monitoring of drought was fewer.

The research on drought in foreign countries started early and produced abundant results and advanced theoretical methods. For example, SÖNmez et al. (2005) used the standardised precipitation index to analyse drought change (Bonaccorso et al., 2003; Patel et al., 2007; Li, 2015;Guo and Wen, 2020). Stewart et al (2020) examined the equity of drought impacts in the watershed between the agricultural, and different urban sectors, and environmental needs. Sam et al (2020) utilized the information on households' perceptions about drought impacts and local adaption and coping measures to analyse the potential determinants that affect the household's preferences for future adaptation and coping strategies. Garcia et al (2017) modified the Thornthwaite scheme to improve the representation of the intra-annual variation of the potential evapotranspiration and improved the low flow simulation in 
hydrological modelling to better characterize the hydrological droughts. Kim et al. (2019) proposed a method to evaluate spatial-temporal droughts based on the water quality risk and to monitor environmental droughts using the probability of exceeding the target water quality to facilitate a resilient proactive response. Greene (2018) examined the drought vulnerability of farmworkers both in the fields and in their communities by analysing how changes in water resources and agricultural practices impact socioeconomic drought. Michael and Lance (2015) found that climate system had warmed sufficiently so that drought should be assessed with the combination of low precipitation and abnormal warmth. Most of the above studies were conducted in small region at a single time scale. However, the spato-temporal rules of drought would be different with the change of time scales, while fewer studies were applied to investigate the difference.

During the past decades, many scholars utilized the satellite images to explore the condition or change patterns of drought. Using TM images, Yang et al. (2011) applied two drought monitoring methods of vertical drought index (PDI) and improved vertical drought index (MPDI) to monitor the drought condition. Guo et al. (2013) analysed the dynamic change of drought in the Yarlung Zangbo River Basin by using the vertical drought index model and the gravity centre model based on MODIS and meteorological data. Zhang et al. (2009) combined the MODIS data and ground observation data to retrieve the actual soil water content. Sun et al. (2010) utilized the MODIS data, normalised difference vegetation index (NDVI) and land surface temperature (LST) to construct feature space and then calculated the TVDI to monitor 
the drought condition. Bai et al. (2019) explored the inter-annual variation characteristics of drought frequency in Northwest China by using the daily meteorological observation data of meteorological stations. Liu (2018) utilized the monthly SPEI dataset from 1901 to 2015 to identify the drought area and drought intensity through the spatial drought feature recognition method. However, the time scale of the most above researches is small because of the limited data sources (remote sensing images and meteorological station data), causing restrictions in revealing the spatio-temporal evolution rules.

Some domestic scholars have explored the drought and flood evolution rules for hundreds of years on the basis of historical documents, opening the possibility of studying the long-term drought events in China. However, fewer studies were investigated to analyse the spatial-temporal change patterns of drought from different time scales. In order to reveal the evolution laws of drought at different time scales, this study introduced the wavelet analysis, Mann-Kendall (M-K) test, and gravity centre model to analyse and discuss the spatio-temporal evolution patterns of drought in China basing on the 1470-2000 long-term series drought dataset of China, and then forecast the possible future drought trend.

\section{Data sources and research methods}

\subsection{Study area}

The study area, located between $18.1^{\circ} \mathrm{N}-45.2^{\circ} \mathrm{N}, 95.9^{\circ} \mathrm{E}-128.3^{\circ} \mathrm{E}$, mainly includes the Liaohe River Basin, the Haihe River Basin, the Huaihe River Basin, the Yellow River Basin, the Yangtze River Basin (excluding the Shigu River Basin of 
Jinsha River), the Southeast River Basin, the Pearl River Basin and the Qinghai Lake

Basin (Figure 1). The climate of the study area is largely affected by the monsoon, with the precipitation ranging 200-1600mm.In addition, the temporal distribution of precipitation differ greatly, which mostly occurs in summer. There is a decreasing trend of precipitation from southeast to northwest in spatial distribution. The aridity in northern part is larger than that of southern part.

\subsection{Data source and pre-processing}

The 113 station datasets of 530-year (1470-2000a, year by year) drought and flood grades in China were obtained from the atlas of drought-flood distribution in China in recent 500 years and China Meteorological Data Network (http://data.cma.cn/) (Figure 1). The detail information mainly includes station name, latitude $\left({ }^{\circ} / \mathrm{N}\right)$, longitude $\left({ }^{\circ} / \mathrm{E}\right)$, recorded time and its drought degree(Table 1). And the drought data were gridded into images with a spatial resolution of $10 \mathrm{~km}$ utilizing the interpolated method of Krigering. The overall interpolated accuracy was $87.2 \%$ with the cross validation method.

\subsection{Methods}

Drought intensity index can better indicate the drought condition in a certain period. Drought risk index can reflect the drought susceptibility in a certain period. The mitigating distance and direction of gravity centre can reflect the imbalance degrees of drought variation inner the study region. Mann-Kendall test can indicate the change trend of the drought during certain period. The Hurst index that derived from rescale range analysis is a measure of time series correlation and trend strength. 
Wavelet transform can be utilized to analyse multiple frequency characteristics of non-stationary time series. Because of its good local properties in both time and frequency domain, we can analyse the local characteristics of the periodic changes of time series to reveal the change of each period with time more clearly.

\subsubsection{Drought intensity index}

Drought intensity index refers to the average drought degree of the whole study region in year $t$ (Hu et al., 2015). The calculation formula of drought intensity index is as follows:

$$
S_{t}=\frac{\sum_{i=1}^{N} Z_{i t}}{N}
$$

where $S_{t}$ represents the drought intensity index of the whole region in year $t$, $Z_{i t}$ represents the attribute value of grid $i$ in year $t$, and $N$ represents the total number of grids in the region.

\subsubsection{Drought risk index}

Drought frequency in a certain area reflects whether or not the area is prone to drought to a certain extent (Zhang et al., 2009; Chen et al., 2013). Drought risk index can be used to express the concept of hazard factors based on gridded datasets. The calculation formula is as follows:

$$
P_{i}=\sum_{t=m}^{m+k} Z_{i t},(2)
$$

where $P_{i}$ represents the drought risk index of grid $i$ from the $m$-th year to the $m$ $+k$ year and $Z_{i t}$ represents the attribute value of grid $i$ in year $t$. 

then the spatial mean value of the region composed of $\mathrm{N}$ plane space elements is defined as a Cartesian coordinate point $(\bar{x}, \bar{y})$, and the calculation formula is as 159 follows:

$$
\bar{x}=\left(\sum_{i=1}^{i=n} z_{i} x_{i}\right) /\left(\sum_{i=1}^{i=n} z_{i}\right)
$$

$$
\bar{y}=\left(\sum_{i=1}^{i=n} z_{i} y_{i}\right) /\left(\sum_{i=1}^{i=n} z_{i}\right)
$$

\subsubsection{Mann-Kendall test}

In the trend analysis of time series, $\mathrm{M}-\mathrm{K}$ test is a nonparametric method recommended by WMO and widely used (Guo et al., 2020a).Suppose there is a stationary independent sequence $x_{t}(\mathrm{t}=1,2,3, \ldots, \mathrm{n})$, the $S$ statistic is defined as

$$
S=\sum_{i=1}^{n-1} \sum_{j=i+1}^{n} \operatorname{sgn}\left(x_{j}-x_{i}\right)
$$

where $\operatorname{sgn}()$ is the symbolic function:

$$
\operatorname{sgn}(\theta)=\left\{\begin{array}{cc}
1 & \theta>0 \\
0 & \theta=0 \\
-1 & \theta<0
\end{array}\right.
$$

When $\mathrm{n} \geq 10$, the statistic $S$ approximately obeys normal distribution, and its mean value $E(S)=0$ does not consider the equivalent data points in the sequence.

The variance of the statistic $S$ is

$$
\sigma^{2}=\frac{n(n-1)(2 n+5)}{18}
$$

The standardised test statistic $\mathrm{Z}$ is calculated as follows: 


$$
\left\{\begin{array}{cl}
\frac{S-1}{\sigma} & S>0 \\
\mathrm{Z}= & S=0 .(8) \\
\frac{S+1}{\sigma} & S<0
\end{array}\right.
$$

$\mathrm{Z}>0$ indicates an increasing trend, whereas $\mathrm{Z}<0$ indicates a decreasing trend. Under the confidential level of $\alpha$, if the $|Z|$ is greater than $Z_{\left(1-\frac{\alpha}{2}\right)}$, then there was a significantly increasing or decreasing trend. $Z_{\left(1-\frac{\alpha}{2}\right)}$ refers to the value of

178 the standard normal distribution when the probability exceeds the $1-\frac{\alpha}{2}$.

179 Therefore, $|Z| \geq 1.29,1.96,2.56$ can indicate that the change trend had reached

180 confidence levels of $90 \%, 95 \%$ and $99 \%$, respectively.

\subsubsection{Rescale range analysis}

The dimensionless ratio $\mathrm{R} / \mathrm{S}$ introduced in the rescale range analysis $(\mathrm{R} / \mathrm{S}$ analysis) is utilized to calculate the rescale range of each sub-sequence and the mean scale range of $K$ subsequences $(R / S)_{n}$ ( $\mathrm{Li}$ and Ma, 2014):

$$
(R / S)_{n}=\frac{1}{K} \sum_{k=1}^{K}\left(R_{k} / S_{k}\right)
$$

By changing the value of $n$, different sub-sequence length $n$ (different time scales) corresponds to different mean rescale ranges $(R / S)_{n}$. Hurst index satisfies the relation $(R / S)_{n}=c \cdot n^{H}$, and the logarithm can be obtained as follows:

$$
\log (R / S)_{n}=\log c+H \log n,(10)
$$

Where $\mathrm{c}$ is a constant, $\log \mathrm{n}$ is the independent variable. The least square estimation is used to fit the line, and the slope of the line $\mathrm{H}$ is Hurst index. 
or a trend component of persistence or anti-persistence can be determined depending on the size of the $H$ value. Different $H$ values correspond to the following situations:

(1) $H=0.5$ indicates that the sequence is a random process, and the current trend does not affect the future.

(2) $0<H<0.5$ means that the time series presents anti-persistence, that is, the future trend is opposite to the past. The closer the $H$ value is to 0 , the stronger the anti-persistence will be.

(3) $0.5<H<1$ indicates that the time series presents continuity, that is, the future trend is the same as the past. The larger the $H$ value is, the more obvious the trend is.

\subsubsection{Wavelet analysis (Morlet)}

Wavelet transform can be used to analyze multiple frequency characteristics of nonstationary time series. In addition, since Morlet continuous complex wavelet transform can give both phase and amplitude information of time series changes, Morlet wavelet function is usually used in the study of climate related series.

where ${ }^{\omega_{0}}$ refers to frequency, dimensionless.

3 Temporal variation characteristics of drought in recent 500 years

\subsection{Drought risk under different time scales}

\subsubsection{Time scale of $100-y e a r$}

The drought risk index of the whole study area was calculated based on five periods of 1470-1569a, 1570-1669a, 1670-1769a, 1770-1869a, and 1870-1969a, as 
shown in Table 2 and Figure 2.

(1) The overall drought risk in the study area during 1470-1569a was relatively high. The mean value of the drought risk index in this period was higher, and the standard deviation was the largest, indicating that the drought risk during this period had a high degree of variation, and the distribution of drought risk was extremely uneven. Figure 2(a) shows the drought risk index of the Qinghai Lake Basin, the eastern part of the Yellow River Basin, the Huaihai Plain, the Liaohe River Basin, the Jinsha River, the upper reaches of the Minjiang River and the Minjiang River Basin was larger .

(2) During 1570-1669a, the drought risk degree decreased. The mean value and standard deviation of drought risk were smaller than those during the previous 100 years. As shown in Figure 2(b), zones with high drought risk were mainly located in the North China Plain and Pearl River Delta and the Qiantang River Basin. In addition, the extent of high drought risk decreased during this period.

(3) During 1670-1769a, the drought risk had been further reduced. The mean value and standard deviation of drought risk in this period were smaller than those in the previous period, and the mean value was the smallest among the five periods. As shown in Figure 2(c), the drought risk index of the Qinghai Lake Basin and the upper reaches of the Jinsha River was relatively larger, whereas that of the other regions was relatively smaller.

(4) During 1770-1869a, the drought risk was generally lower. The standard deviation was smaller than that of the previous period, and its maximum value was 
the smallest among the five periods. As was shown in Figure 2(d), only the Qinghai Lake Basin, the upper reaches of the Jinsha River Basin and the southern part of the Haihe River Basin had higher drought risk, whereas the other areas had lower drought risk.

(5) During 1870-1969a, the drought risk was generally higher. The maximum and mean values were the largest among the five periods, whereas the standard regions.

\subsubsection{Time scale of 50-year}

The drought risk index was calculated based on 10 periods of $1470-1519$ a, 1520-1569a, 1570-1619a, 1620-1669a, 1670-1669a, 1770-1769a, 1770-1819a, 1820-1869a, 1870-1919a and 1920-1969a, and then the variation characteristics of the drought risk in the 50-year scale were analysed, as shown in Table 3 and Figure 3.

(1) During 1470-1519a, the drought risk was generally higher. The maximum value, mean value and standard deviation in this period were the largest among the 10 periods, indicating larger spatial heterogeneity of drought risk inner the study area. As 
study area, mainly distributed in the Qinghai Lake Basin, the upper reaches of the Yangtze River and the Yellow River Basin.

(2) During 1520-1569a, the drought risk decreased to some extent. The mean value and standard deviation of drought risk were lower than those of the previous period. As shown in Figure 3(b), regions with higher drought risk in the study area were distributed in the Hetao Plain, the Liaohe River Basin and the Hongze Lake Basin.

(3) During 1570-1619a, the drought risk had been further reduced. As shown in Figure 3(c), the drought risk of Liao River basin and the central area of the Huang-Huai-Hai Plain was higher during this period.

(4) During 1620-1669a, the drought risk showed an increased trend. The average drought risk was higher than that of the previous 50 years. As shown in Figure 3(d), the drought risk was higher in the eastern Loess Plateau, the Pearl River Delta and the lower reaches of Qiantang River.

(5) During 1670-1719a, the drought risk had been reduced with the decreasing of mean value and standard deviation of drought risk As shown in Figure 3(e), the drought risk of the Qinghai Lake Basin, the upper reaches of the Jinsha River Basin and the southeast coastal areas was relatively higher during this period.

(6) During 1720-1769a, the drought risk i was relatively lower. The mean value in this period was the lowest among the 10 periods, and the standard deviation was lower than that of the previous 100 years. As shown in Figure 3(f), zones with higher drought risk were mainly located in the west of the Liaohe River Basin, the north of 
the Haihe River Basin and the Hetao Plain.

284

285

286

(7) During 1770-1819a, the drought risk showed a slightly increased trend. In this period, the maximum value of drought risk was the lowest among the 10 periods, with an increase in mean value and a decrease in standard deviation compared with the previous period. As shown in Figure 3(g), zones with higher drought risk were distributed in the eastern Loess Plateau and the central Huaihai Plain.

(8) During 1820-1869a, the drought risk was basically the same as that in the previous period. The mean value changed slightly, and the standard deviation showed an decreasing tend. As shown in Figure 3(h), only a small area in the south of the Haihe Plain had a slightly higher drought risk than the other areas.

(9) During 1870-1919a, the drought risk in the study showed an increased trend. The standard deviation of drought risk was smaller, whereas the mean value was larger. As shown in Figure 3(i), the zones with higher drought risk were mainly concentrated in the west of the Loess Plateau and the east of the Pearl River Basin.

(10) During 1920-1969a, the drought risk had been further increased. In this period, the mean value of drought risk was the largest, whereas the standard deviation was the smallest among the 10 periods. This indicated that the spatial heterogeneity. of drought risk became larger. Figure 3(j) showed that zones with higher drought risk were mainly distributed in the west of the Liaohe River Basin, the Yellow River Basin, the south of the Haihe River Basin, the Huaihe River Basin, the Wujiang River Basin and the lower reaches of the Yangtze River.

\subsection{Variation characteristics of drought intensity}



area. The larger the index value is, the more severe the drought will be. To better analyse the characteristics of inter-annual variation of drought intensity, this study calculated the drought intensity index of different study periods. The closer the drought intensity index is to 3 , the lower the drought intensity index is and vice versa. As shown in Figure 4, the drought intensity showed an overall trend of fluctuating increase during the past 500 years. The minimum value was 3.001 in $1761 \mathrm{a}$, whereas the maximum value was 4.295 in 1640 a, when the Ming Dynasty perished, and this drought was one of the main reasons that it fell. The estimated linear trend of drought intensity from $1470 \mathrm{a}$ to $2000 \mathrm{a}$ was 0.0004 , and the upward trend was weak. However, the drought intensity index during the past 100 years was higher than that of the previous 400 years. 


\section{Spatial variation characteristics of drought in recent 500 years}

\subsection{Spatial distribution characteristics of average drought degree}

The spatial distribution of average drought degree from 1470a to 2000a was calculated. As shown in Figure 6, the drought in northern parts was the most serious during 1470-2000a with a value of 3.844. Among them, the Qinghai Lake Basin, the Yellow River Basin, the western parts of the Liaohe River Basin and the Haihe River Basin was high, whereas that of the eastern part of the Liaohe River Basin and the Huaihe River Basin had more serious drought. On the contrary, the drought condition in the southeast coastal area was slight with the value of 3.5.

\subsection{Gravity centre of drought on different time scales}

\subsubsection{Spatial disturbution of gravity centre of annual drought during 1470-2000a}

The gravity centre of drought can effectively reflect the imbalance and bias of the spatial distribution of drought degree in the study area. Utilizing the gravity centre model, the annual drought gravity centres in the study area from 1470a to 2000a were calculated. As shown in Figure 7, the red dot represented the gravity centre of average drought from $1470 \mathrm{a}$ to $2000 \mathrm{a}$, and the green dot represented the gravity centre of drought for each year. Most of the gravity centres of drought were concentrated in Nanyang City, Henan Province.

Coordinate system A was established with the gravity centre of annual drought as the origin to explain the spatial distribution characteristics of the drought gravity centre during the past 500 years. The numbers of drought gravity centres located in different quadrants of the coordinate system and their percentages were counted and 
calculated. The results showed that (Figure8(a)): Among them, the numbers of drought gravity centres in the southeast and northwest quadrants were the largest,

351 accounting for $29.38 \%$ and $26.93 \%$, respectively, indicating that the drought in the

352 southeast and northwest of the study area was more serious. Meanwhile, the numbers

353 of drought gravity centres in the northeast and southwest quadrants were relatively

354 small, accounting for $22.41 \%$ and $21.28 \%$, respectively.

Since China was significantly affected by the monsoon, the coordinate system A was rotated $45^{\circ}$ counter clockwise to obtain coordinate system $B$. The number of drought gravity centres in each quadrant and their percentages were counted and calculated. The results showed that (Figure 8 (b)): The proportion of drought gravity centres in the south quadrant was the largest with $31.26 \%$, followed by that of north quadrant $(28.25 \%)$ and west quadrant $(21.09 \%)$, while the proportion of drought gravity centres in east quadrant was the smallest with the value of $19.40 \%$. The study area could also been divided into two parts according to the coordinate axes. In particular, it should be noted that the proportion of drought gravity centres in the northeast quadrant (47.65\%) was larger than that in the southwest quadrant $(52.35 \%)$, which showed that the drought in the southwest of the study area was more serious than that in the northeast.

\subsubsection{Migration trajectory of drought gravity centres on different time scales} this study analysed the migration direction of drought gravity centres on different time scales from 1470a to 2000a. Considering the influence of extreme climate and other 
factors on the changes of drought gravity centres, the migration trajectories of drought gravity centres were investigated on two time scales (100a and 50a). As shown in Figure 9, on the 100-year scale, the gravity centre of the drought in 1570-1669a moved towards the southeast compared with that in $1470-1569 \mathrm{a}$, while the migration directions of gravity centre of $1570-1669 a \rightarrow 1670-1769 a$ and $1670-1769 a \rightarrow 1770$ -1869 a were consistent (moving toward northwest). Meanwhile, the gravity centre in 1870-1969a shifted to the southwest compared with that in 1770-1869a. In general, the gravity centre of drought moved toward the southwest. As shown in Figure 9, on the 50-year scale, the gravity centre of drought moved towards first to the northeast (1520-1569a), then to the north (1570-1619a), southwest (1620-1669a), southeast (1670-1719a), northwest (1720-1769a), southwest (1770-1819a), southeast (1820-1869a), southwest (1870-1919a), and finally to the northwest (1920-1969a). Among them, four periods of northward migration and five periods of southward migration were found, which indicated that the drought in the south become more serious than before.

\section{Trend predication of drought intensity on different time}

\section{scales}

\subsection{Trend prediction of drought intensity for the whole region}

Based on drought intensity index from 1470a to 2000a, linear trend estimation, $\mathrm{M}-\mathrm{K}$ test and rescaled range analysis were carried out. The trend statistics value of 0.0004 in the whole region was obtained, indicating that the increasing trend was slight, whereas the $\mathrm{Z}$ statistic value was 5.873 , indicating that the increasing trend 
reached the confidential level of $99 \%$. Meanwhile, the Hurst index was 0.667, indicating that the drought aggravation trend would continue in the future.

\subsection{Trend predication of drought intensity on 100-year scale}

The series of drought intensity index in 1470-1569a, 1570-1669a, 1670-1769a, 1770-1869a and 1870-1969a were discussed by linear trend estimation, M-K test and $\mathrm{R} / \mathrm{S}$ analysis. As shown in Table 4, the drought intensity showed a decreasing trend in $1470-1569 \mathrm{a}$ with the confidence level of $99 \%(|Z|>2.56)$, which indicated that the decreasing trend was extremely significant during this period. During 1570-1669a, the drought intensity showed an increasing trend with the confidential level of $90 \%(|Z|>1.29)$, which indicated that the increasing trend of drought was slightly significant during this period. During 1670-1769a, the drought intensity also showed a decreasing trend, and the $\mathrm{Z}$ statistic $(>1.96)$ reached the confidence level of $95 \%$, which indicated that the decreasing trend was more significant during this period. During 1770-1869a, the drought intensity showed an increasing trend with the confidential level of $90 \%(|\mathrm{Z}|>1.29)$, which indicated that the increased trend was slightly significant. In addition, during 1870-1969a, the drought intensity showed a significantly increasing trend with the confidential level of $99 \%$. Among the five periods, only the Hurst index of 1770-1869a was less than 0.5, and the others were all greater than 0.5 , which indicated that the change trend of drought intensity was not random and had inherent persistence in the 100-year scale.

\subsection{Trend predication of drought intensity on 50-year scale}

As shown in Table 5, the drought intensity showed decreasing trend in the 
periods of 1470-1519a, 1620-1669a, 1720-1769a, while all the change trends were not significant with $|\mathrm{Z}|<1.29$. During $1770-1819 \mathrm{a}$ and $1820-1869 \mathrm{a}$, the increasing trend of drought intensity was not obvious with $|Z|<1.29$. During 1520-1569a, the drought intensity showed a decreasing trend with the confidential level of $99 \%(|Z|>2.56)$, indicating that change trend was extremely significant during this period. During 1570-1619a and 1870-1919a, there was an increasing trend with the confidential level of $90 \%(|Z|>1.29)$, indicating that the change trend was slightly significant in this period. During 1670-1719a and 1920-1969a, the drought intensity showed a decreasing trend with the confidential level of $90 \%(|Z|>1.29)$, indicating that the change trend was slightly significant in this period. In these 10 periods, only the Hurst index during 1770-1819a was less than 0.5, and the others were greater than 0.5 , which indicated that the change trend of drought intensity was not random and was inherently persistent on 50-year scale.

\section{Discussions}

\subsection{Impacts of East Asian Summer Monsoon}

Due to the difference in heat capacity between land and sea, there were differences in sea and land temperature in winter and summer. Therefore, a wide range of prevailing wind patterns with significant seasonal changes were formed in the near strata, which were called monsoons (Shi, 2011). The monsoon blowed from the sea to the land in summer and from the land to the sea in winter. China was in the East Asian monsoon region, and the East Asian summer monsoon referred to the southerly wind prevailing in the summer in East Asia (Shi, 2019). The summer monsoon in the eastern part of China was mainly easterly and southward. Many researchers analyzed the evolutions of the East Asian summer monsoon, and found 
that the intensity of the east Asian summer monsoon had significant cyclical variation characteristics of 60-70a, 30-40a and 10-20a (Zhang and Liu, 1993). The intensity, onset time and duration of the East Asian summer monsoon had great influence on the distribution of summer precipitation in China. When the East Asian summer monsoon was strong, the southerly wind would transported the abundant water vapor from the ocean to the inland areas, and the precipitation in North China would increase, while there would be less precipitation and high temperature in the Jiang-Huai region. On the contrary, there would be more precipitation in the south and less precipitation in the north, and the temperature would be higher in the north than in the south. The historical drought stage and the time span of spatio-temporal clustering had a certain matching relationship with the variation period of East Asian summer monsoon. From the 16 th century to the first half of the 17 th century and from the 18th century to the first half of the 19th century, the northern part of the study area was prone to drought disasters, corresponding to the weak period of the East Asian summer monsoon. From the second half of the 17 th century to the beginning of the 18th century and from the end of the 19th century to the 20th century, the southern part of the study area was prone to drought disasters, corresponding to the strong period of the East Asian summer monsoon.

\subsection{Impacts of Ocean Heat}

The variation of ocean thermal conditions and sea-air interaction were considered to be important factors for short-term climate change. The precursors of climate anomalies could often be found in ocean changes (Zhang et al.,2003). Among them, ocean surface temperature was one of the factors that had important influence on atmospheric circulation, which had become an important reference index for precipitation prediction. The E1 Nino-Southern Oscillation (ENSO) was a cycle process occurring in the tropical Pacific region, and its period was 2-8a. It could be indicated by the variation of SST in the eastern Equatorial Pacific Region and surface pressure in the equatorial western Pacific. ENSO had an important impact on the global climate (Hu et al., 2015). For China, when ENSO was in the development stage 
and the SST of the tropical Middle East and Pacific was relatively high, the summer precipitation was relatively scare in north China and south China, where was prone to drought. Researchers found that the SST variation in the equatorial eastern Pacific Ocean had a periodicity of $2 \mathrm{a}$ and 3-7a. The Southern oscillation also had a variation cycle period of 2-4a. SST in the Indian Ocean could also affect the summer precipitation in China (Li, 2015). When the SST in the south Equatorial Indian Ocean was warmer, the East Asian summer monsoon would arrive later than normal, withdraw earlier, and the monsoon season was shorter and weaker(Ren et al.,2005). The corresponding North China had rare precipitation and was prone to drought. In addition, the North Atlantic Oscillation and other factors were also believed to influence the summer precipitation in eastern China. The spatial pattern of drought in the study area had a significant change period of about 2-4 years and 8 years in the East-West and northeast-southwest directions, and 5-6 years in the Northwest -southeast direction. In a short time scale, the change of drought intensity and spatial pattern in the study area was mainly affected by the change of ocean heat condition.

\subsection{Impacts of Climate Change}

According to the IPCC's fifth assessment report, most of the world had experienced the process of warming in the past hundred years. During 1880-2012a, the global average temperature increased by $0.85^{\circ} \mathrm{C}(\mathrm{Xu}$ et al., 2015). The frequency and intensity of extreme weather events, such as extreme droughts and high temperatures, showed an increasing trend (Wang et al., 2015). In this paper, the drought on the whole had an obviously increasing trend. The drought intensity was the most severe from 1870a to 1969a, which was also consistent with the conclusion of many scholars that China entered a warm period in the early 20th century (Zhang et al., 2003). The droughts in 1670-1769a and 1770-1869a were less severe than those in 1470-1569a and 1570-1669a. Some studies in the field of climatology also believed that the climate in Qing Dynasty was wetter than that in Ming Dynasty(Li, 2015).

\section{Conclusions}

In this study, the gravity centre model, wavelet analysis, and Mann-Kendall 
$(\mathrm{M}-\mathrm{K})$ test were introduced to explore the change patterns of drought on multiple spatio-temporal scales during 1470-2000a and the possible future drought trend was predicted. The main conclusions were as follows:

(1) The zones with the highest drought risk were distributed in the northern parts, which mainly included the Qinghai Lake Basin, the Yellow River Basin, the Haihe River Basin, the Western Liaohe River Basin and the Huaihe River Basin. During 1470-2000a, the drought intensity index showed an increasing trend. There were three main cycles from 1470 to 2000, with time scales of 99a, 270a and 453a.

(2) The spatial distribution of drought was uneven during the past 500 years. The drought intensity in the north was larger than that in the south, which showed a significantly increasing trend.

(3) The gravity centres of drought were mostly distributed in Nanyang city, Henan Province. The migration trajectory of the gravity centre of the drought showed some differences on the 100-year scale and the 50-year scale, but they all showed a trend of south-westward movement.

(4) During 1470-2000a, there was a slightly increasing trend of drought intensity with the confidential level of $99 \%$.And the drought aggravation trend would continue in the future. Although, the variation characteristics of drought on 50-year and 10-year scale were different, the change trend was not random and had inherent persistence.

\section{Acknowledgments}

This work was supported by the Open Fund of Key Laboratory of National Geographic Census and Monitoring, Ministry of Natural Resources (grant no. 
2020NGCM02); Open Research Fund of the Key Laboratory of Digital Earth Science,

Chinese Academy of Sciences (grant no. 2019LDE006); Open Fund of Key

Laboratory for Digital Land and Resources of Jiangxi Province, East China University of Technology (grant no. DLLJ202002); Open foundation of MOE Key Laboratory of

Western China's Environmental Systems, Lanzhou University and the fundamental

Research funds for the Central Universities (grant no. lzujbky-2020-kb01);

University-Industry Collaborative Education Program (grant no.201902208005);

Open Fund of Key Laboratory of Meteorology and Ecological Environment of Hebei

Province(grant no. Z202001H); Open fund of Key Laboratory of Land use,

MNR(grant no.20201511835) ;Open Fund of Key Laboratory of Geomatics and

Digital Technology of Shandong Province; Open Fund of Key Laboratory of

Geomatics Technology and Application Key Laboratory of Qinghai Province (grant no. QHDX-2019-04); Natural Science Foundation of Shandong Province (grant no.

ZR2018BD001).

\section{Data availability statement}

corresponding author, Guo B, upon reasonable request. And the dataset is available at

“https://pan.baidu.com/s/1iq-KE-WxRNudlIM76dxnLg".

\section{References}

Bonaccorso, B, Bordi I, Cancelliere A, Rossi G, Sutera A.2003. Spatial variability of drought: an 

Meteorol.37 (05):722-728.

Bai XY, Shen W, Xu XQ, Peng W. 2020.Applicability of long-term satellite-based precipitation products for drought indices considering global warming. J. Environ. Manage, 255:109846. Index (TVDI) in grassland drought monitoring. Arid.Land. Geogr.36 (05): 930-937.

Garcia PM, Nicolas AL, Velazquez MP. 2017. Combined use of relative drought indices to analyze climate change impact on meteorological and hydrological droughts in a Mediterranean basin.

Greene C. 2018. Broadening understandings of drought -The climate vulnerability of farmworkers

Guo B, Tao HP, Jiang L, Kong B, Liu BT, Shi Z, Song CF. 2013. Research on dynamic monitoring

Guo B, Zang WQ, Luo W. 2020b. Spatial-temporal shifts of ecological vulnerability of Karst 
Guo B, Zang WQ, Yang F, Han BM, Chen ST, Liu Y, Yang X, He TL, Chen X, Liu CT, Gong R. 2020c. Spatial and temporal change patterns of net primary productivity and its response to climate change in the Qinghai-Tibet Plateau of China from 2000 to 2015.J.Arid Land, 12(1):

Guo B, Zang WQ, Yang X, Huang XZ, Zhang R, Wu HWi, Yang LA, Wang Z, Sun GQ, Zhang Y. 2020d.Improved evaluation method of the soil wind erosion intensity based on the cloud-AHP model under the stress of global climate change. Sci.Total Environ. 746: 141271.

Hu S, Mo XG, Lin ZH. 2015. Temporal and spatial variation trend of drought in northern China under future climate scenarios. Arid.Land.Geogr.38 (02):239-248.

Liu XY, Li DL, Wang JS. 2012. Temporal and spatial variation characteristics of regional drought in China from 1961 to 2009. J.Desert.Res. 32 (02):473-483.

Li WJ. 2015. Study on temporal and spatial characteristics and evolution law of Historical Drought Disasters. University of Chinese Academy of Sciences.

Liu XY. 2018. Analysis of spatial and temporal variation characteristics of drought in China in the past 100 years based on SPEI. J.Water.Resour.Archit. Eng.16 (05):228-232.

Li DK, Ma TT. 2004. Analysis of hydrological series change characteristics based on Kendall and R/S method. Sichuan. Water .Conser. 41 (02): 81-82 .

Patel NR, Chopra P, Dadhwal, VK. 2007. Analyzing spatial patterns of meteorological drought using standardized precipitation index. Meteorol.Appl. 14(4): 329-336.

Kim JS, Jain S, Lee JH, Chen H, Park SY. 2019. Quantitative vulnerability assessment of water quality to extreme drought in a changing climate. Ecolo.Indic, 103:688-697. 
Michael BR, Lance M L.2015.Uniqueness and Causes of the California Drought. Procedia. Computer. Sci, 61:428-435.

Ren GY, Guo J, Xu MZ, Chu ZY, Zou XK, Li QX, Liu XN. 2005. Climate changes of China's mainland over the past half century. Acta. Meteorol. Sin. 06: 942-956.

Sam AS, Padmaja SS, Kächele H, Kumar R, Müller K.2020.Climate change, drought and rural communities: Understanding people's perceptions and adaptations in rural eastern India. Int. J. Disast.Risk.Re, 44:101436.

Sergio MVS, Steven MQ, Marina PG, Yuan SS, Fernando DC.2020. A review of environmental droughts: Increased risk under global warming? EARTH-SCI REV,201:102953.

SÖNmez FK, KÖMÜSCÜ A, Erkan A. 2005. An Analysis of Spatial and Temporal Dimension of Drought Vulnerability in Turkey Using the Standardized Precipitation Index. Nat.Hazards. $35(2), 243-264$.

Stewart IT, Rogers J, Graham A. 2020.Water security under severe drought and climate change: Disparate impacts of the recent severe drought on environmental flows and water supplies in Central California. J.Hydro.X, 7:100054.

Sun L, Wu Q, Pei ZY, Pan JW. 2010. Relationship between Temperature Vegetation Drought Index (TVDI) and multiple factors. Geog. Geo-Information Sci. 26 (02): 31-34.

Shi WY. 2011. Research on flood and drought disasters in Chaohu basin since 600 years Shanghai Normal University.

Shi K. 2019. Analysis of spatiotemporal variation and climate driven causes of drought in Northeast China. Dalian University of technology.

Wang L, Liu DD, Li TY, Wang JS, Li LY. 2015. Precipitation trend analysis of Beijiang River 
Xu K, Yang D， Yang H.2015. Spatio-temporal variation of drought in China during 1961-2012: A climatic perspective. J Hydrol. 526 (3):253-264. drought monitoring in Inner Mongolia. Geomat.Inform. Sci.Wuhan Univ. 36 (02): 195-198.

Zhang DE, Liu CZ. 1993. Supplement to the atlas of drought and flood distribution in China in the past 500 years (1980-1992). Meteorol. 19 (11):41-45. China in recent 500 years (1993-2000). J.Appl.Meteorol.Sci. 14 (3): 379-388. 
Figures

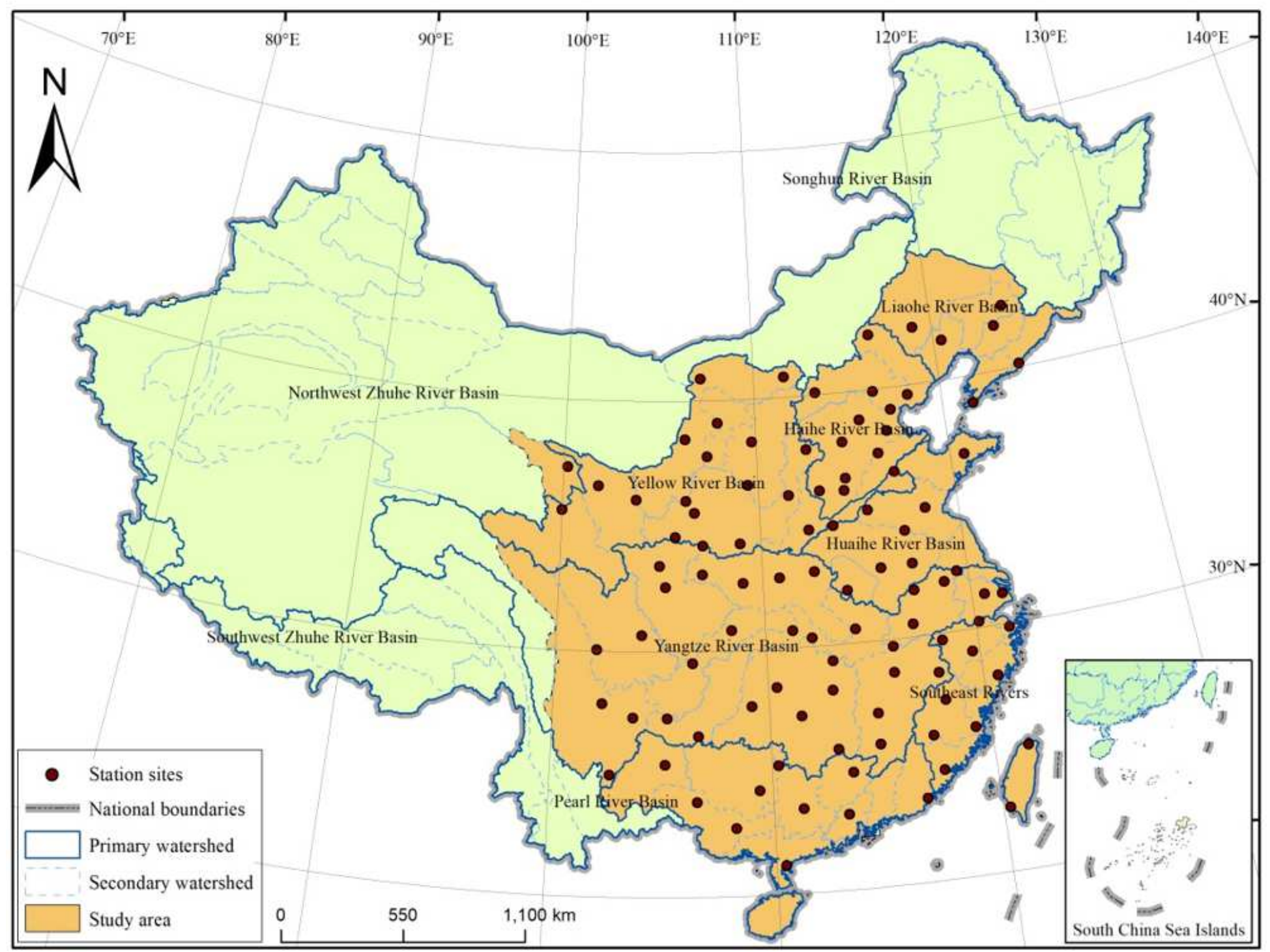

Figure 1

Overview of the study area and distribution of statistical sites. Note: The designations employed and the presentation of the material on this map do not imply the expression of any opinion whatsoever on the part of Research Square concerning the legal status of any country, territory, city or area or of its authorities, or concerning the delimitation of its frontiers or boundaries. This map has been provided by the authors. 

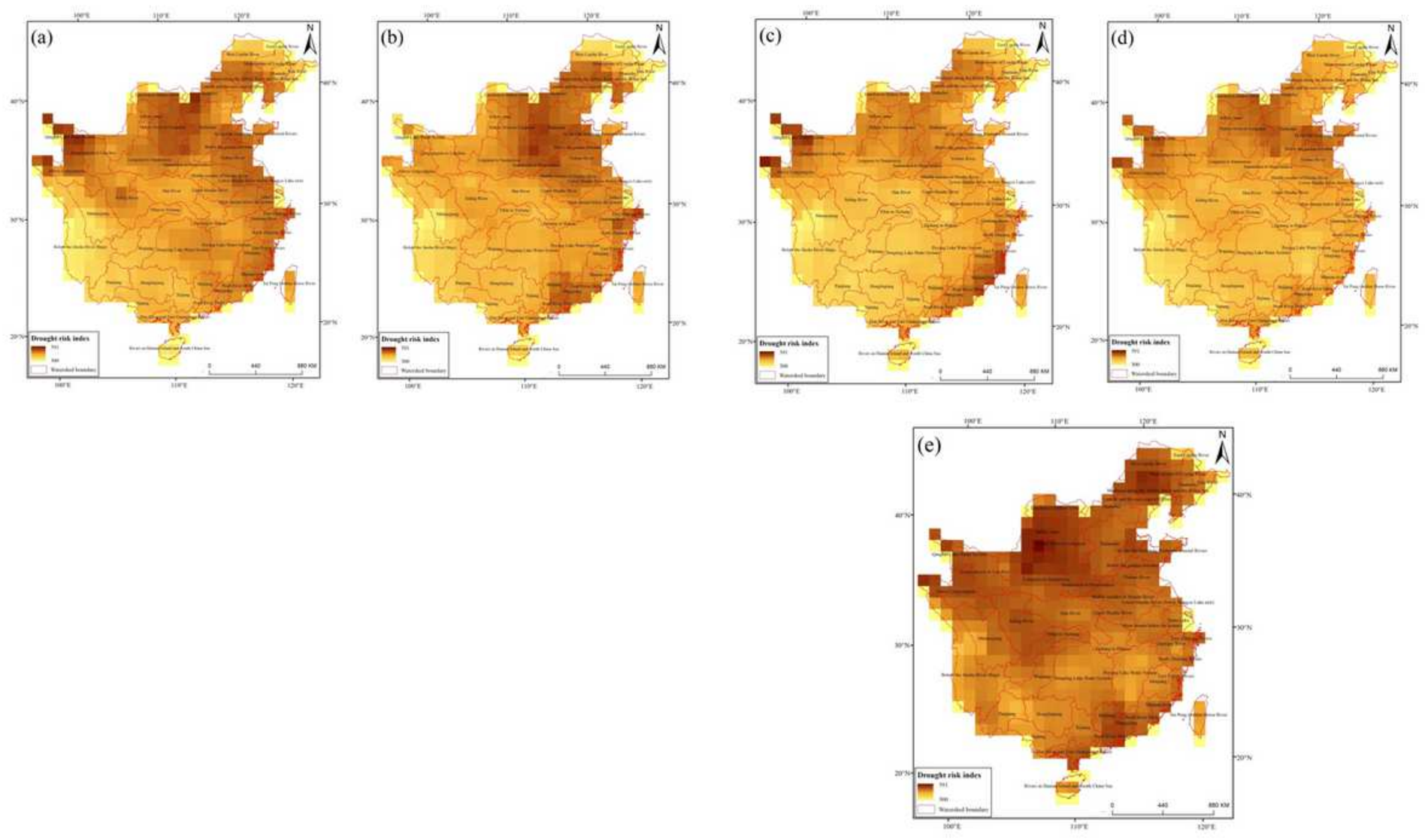

\section{Figure 2}

Drought risk index on 100-year scale (a)1470-1569a, (b) 1570-1669a, (c) 1670-1769a, (d) 17701869a, (e) 1870-1969a. Note: The designations employed and the presentation of the material on this map do not imply the expression of any opinion whatsoever on the part of Research Square concerning the legal status of any country, territory, city or area or of its authorities, or concerning the delimitation of its frontiers or boundaries. This map has been provided by the authors. 

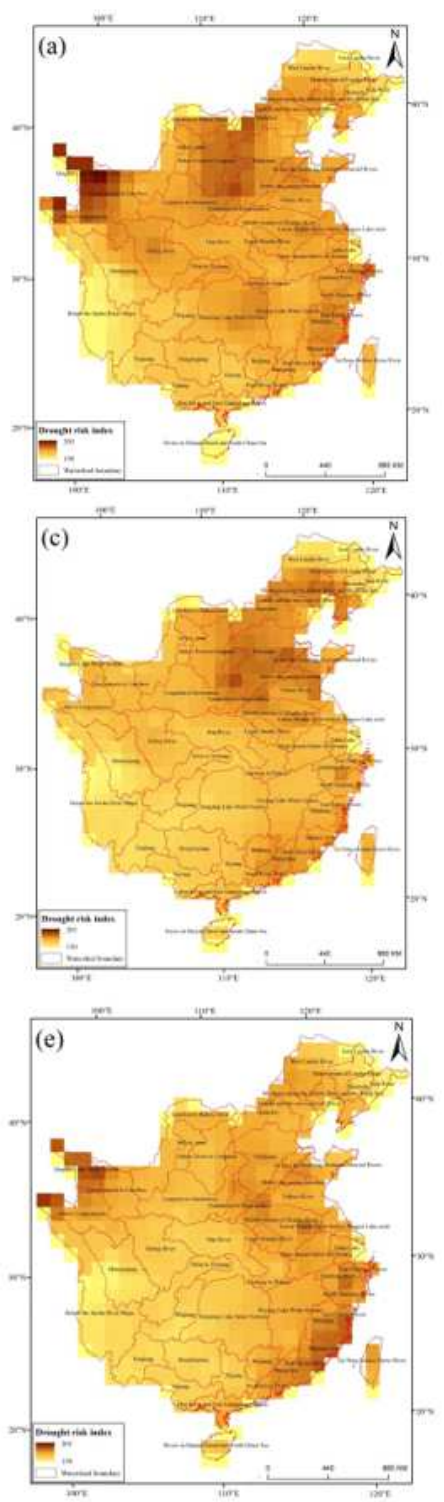
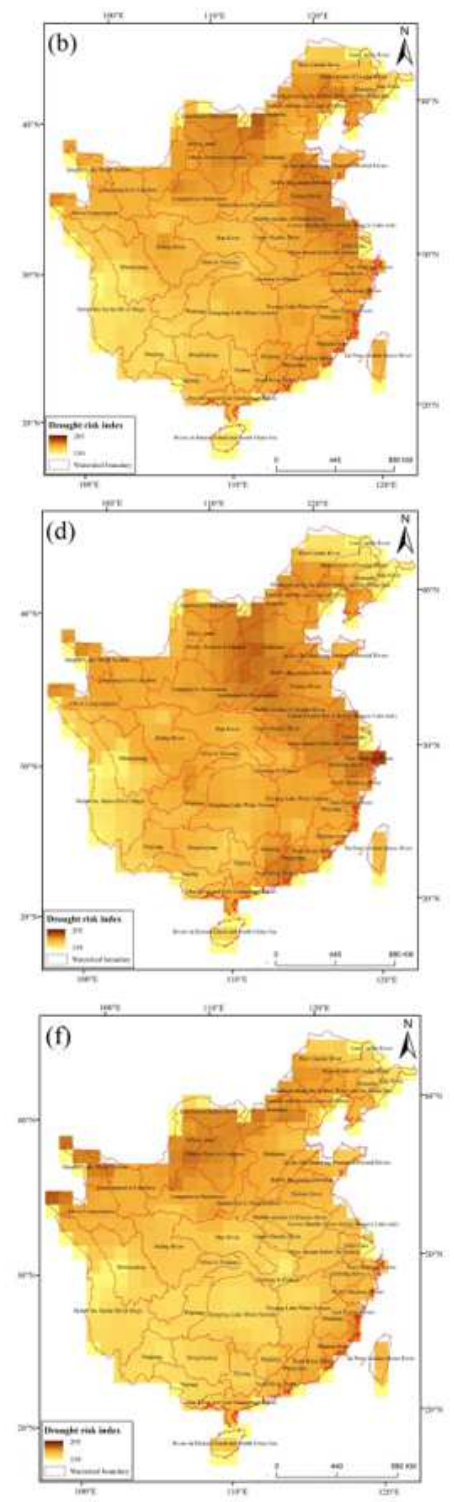
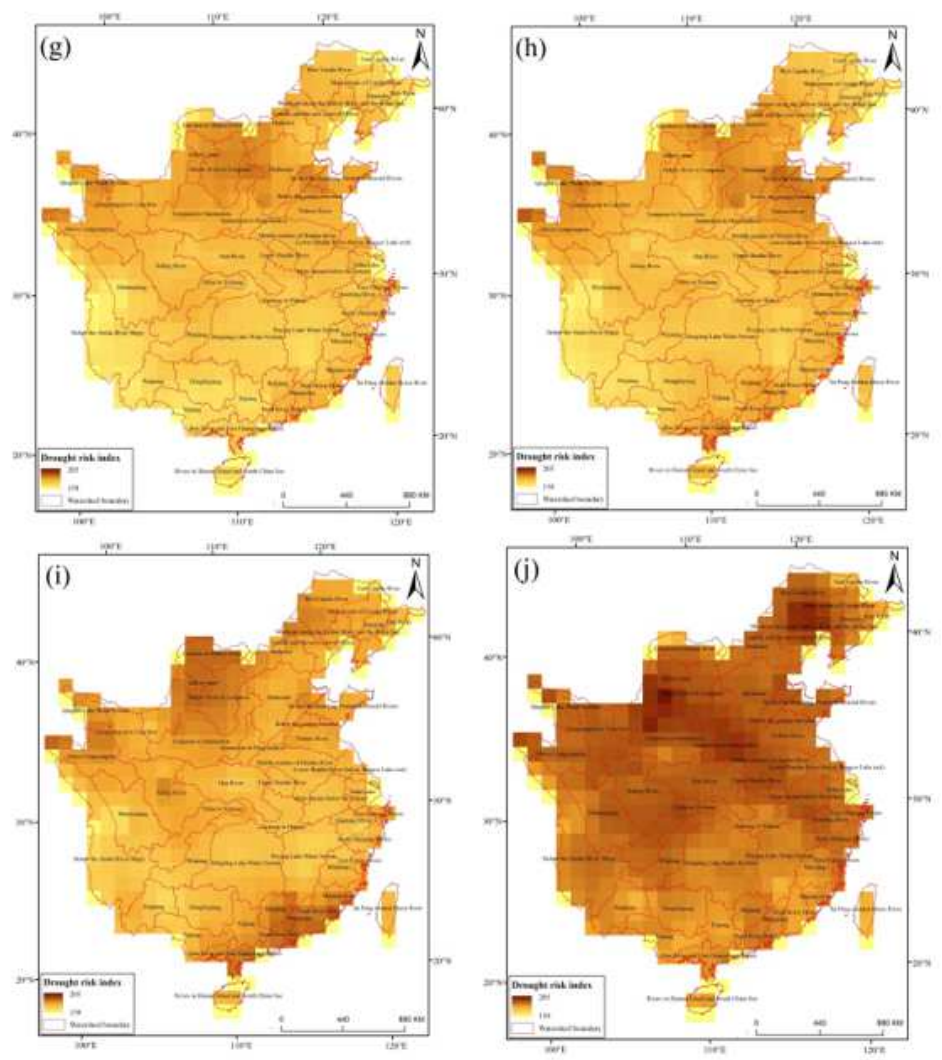

\section{Figure 3}

Drought risk index on 50-year scale (a)1470-1519a, (b) 1520-1569a, (c) 1570-1619a, (d) 1620-1669a, (e) 1670-1719a, (f) 1720-1769a, (g)1770-1819a, (h) 1820-1869a, (i) 1870-1919a, (j) 1920-1969a. Note: The designations employed and the presentation of the material on this map do not imply the expression of any opinion whatsoever on the part of Research Square concerning the legal status of any country, territory, city or area or of its authorities, or concerning the delimitation of its frontiers or boundaries. This map has been provided by the authors. 


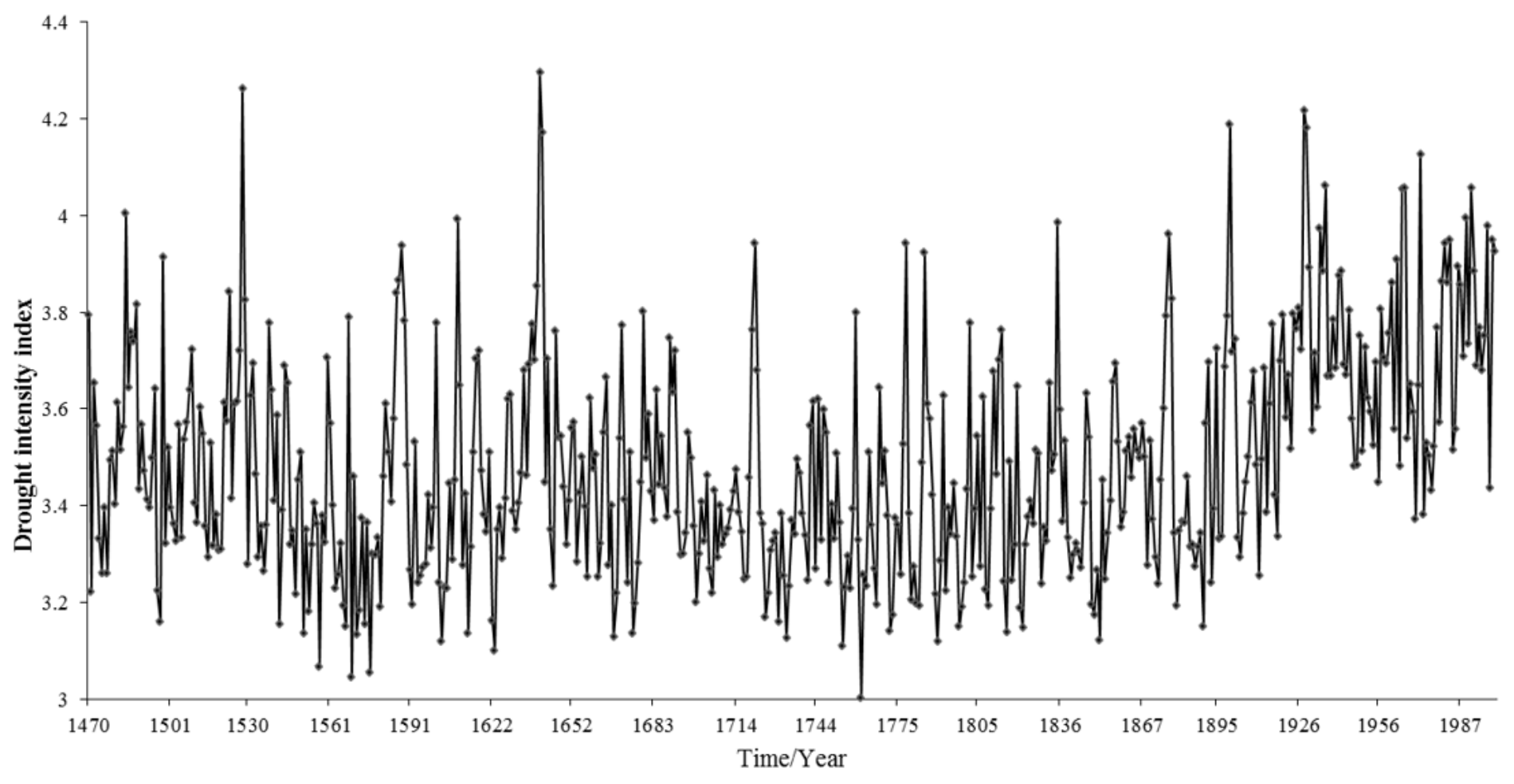

Figure 4

Temporal characteristics of annual variation of drought intensity index.
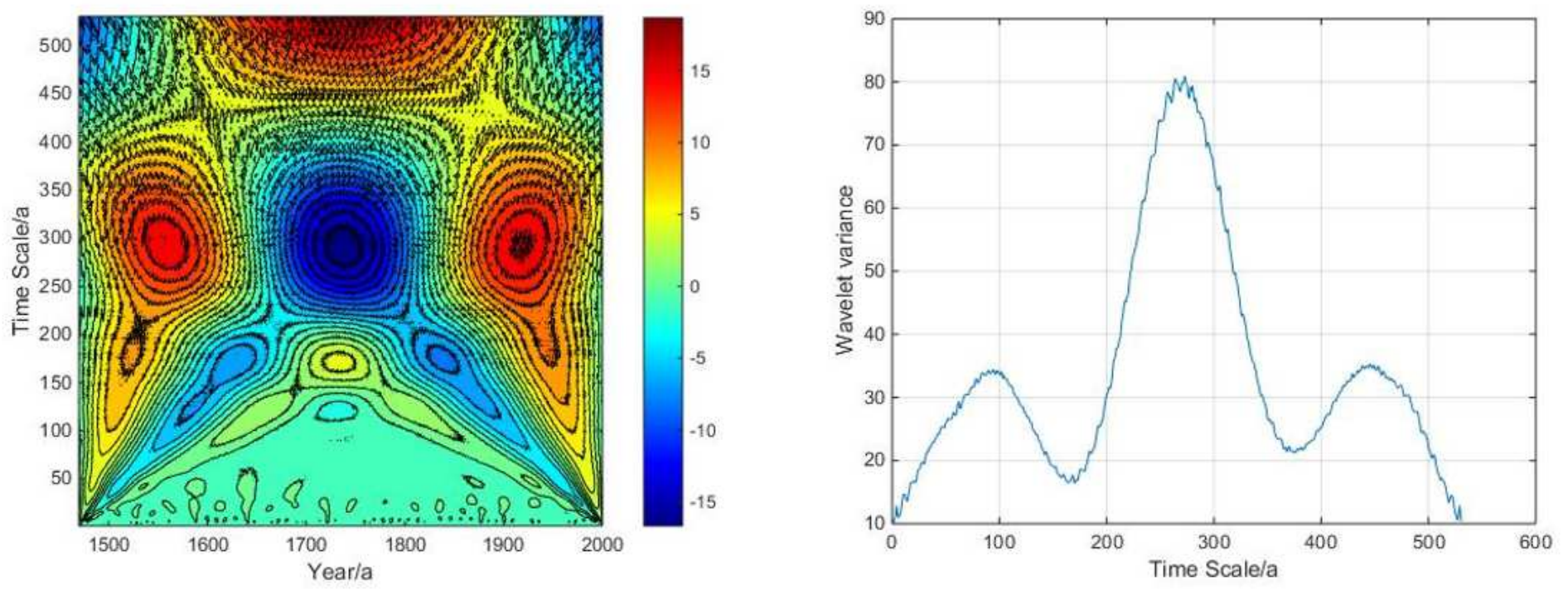

Figure 5

Real part and variance of drought intensity index wavelet analysis from 1470 to 2000 . 


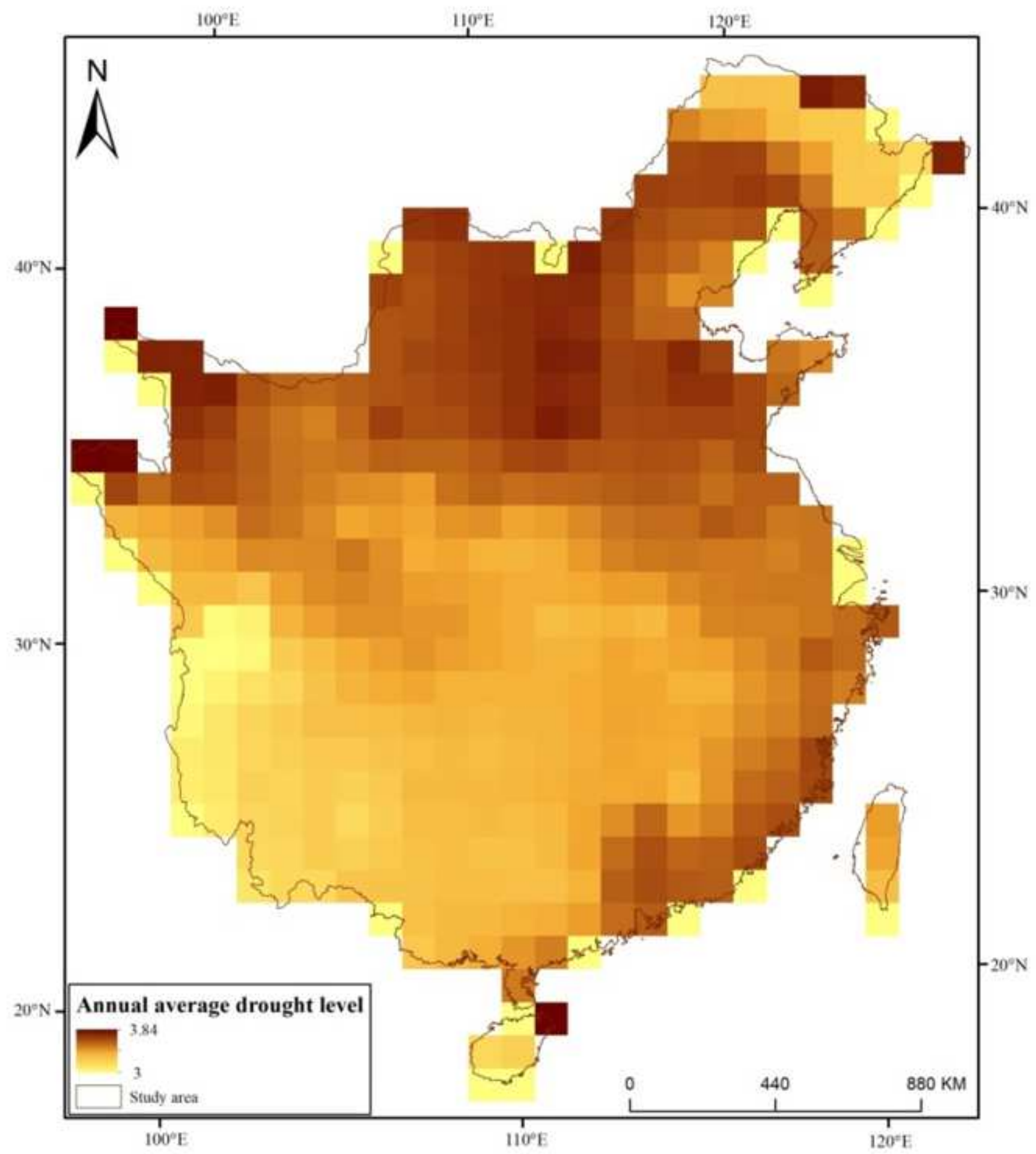

\section{Figure 6}

Spatial distribution of average annual drought degree in recent 500 years. Note: The designations employed and the presentation of the material on this map do not imply the expression of any opinion whatsoever on the part of Research Square concerning the legal status of any country, territory, city or area or of its authorities, or concerning the delimitation of its frontiers or boundaries. This map has been provided by the authors. 


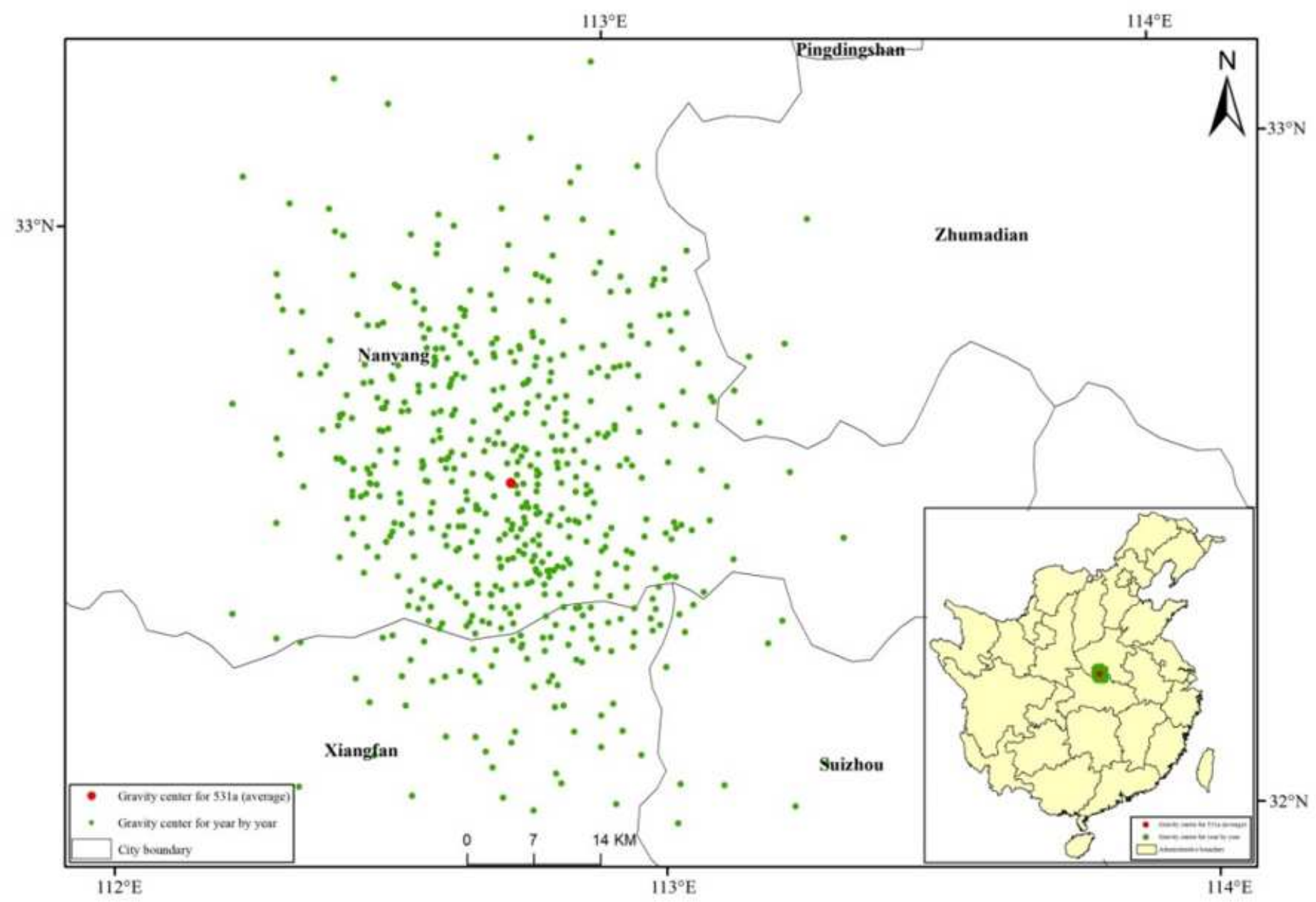

Figure 7

Distribution of drought gravity centre from 1470 to 2000. Note: The designations employed and the presentation of the material on this map do not imply the expression of any opinion whatsoever on the part of Research Square concerning the legal status of any country, territory, city or area or of its authorities, or concerning the delimitation of its frontiers or boundaries. This map has been provided by the authors. 

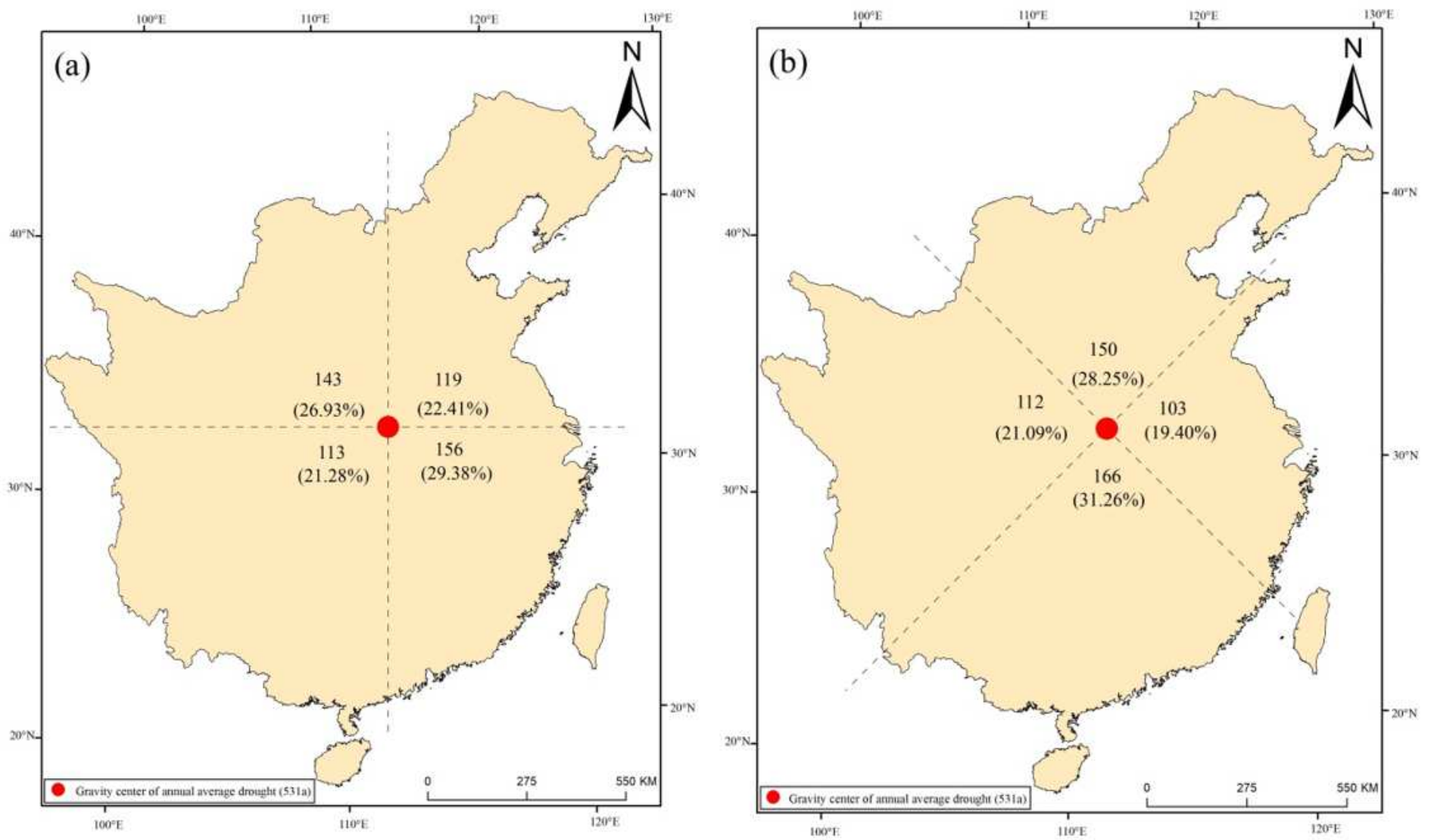

Figure 8

Distribution proportion of drought gravity centers during 1470-2000: (a) Ortho axis; (b) Oblique axis. Note: The designations employed and the presentation of the material on this map do not imply the expression of any opinion whatsoever on the part of Research Square concerning the legal status of any country, territory, city or area or of its authorities, or concerning the delimitation of its frontiers or boundaries. This map has been provided by the authors. 


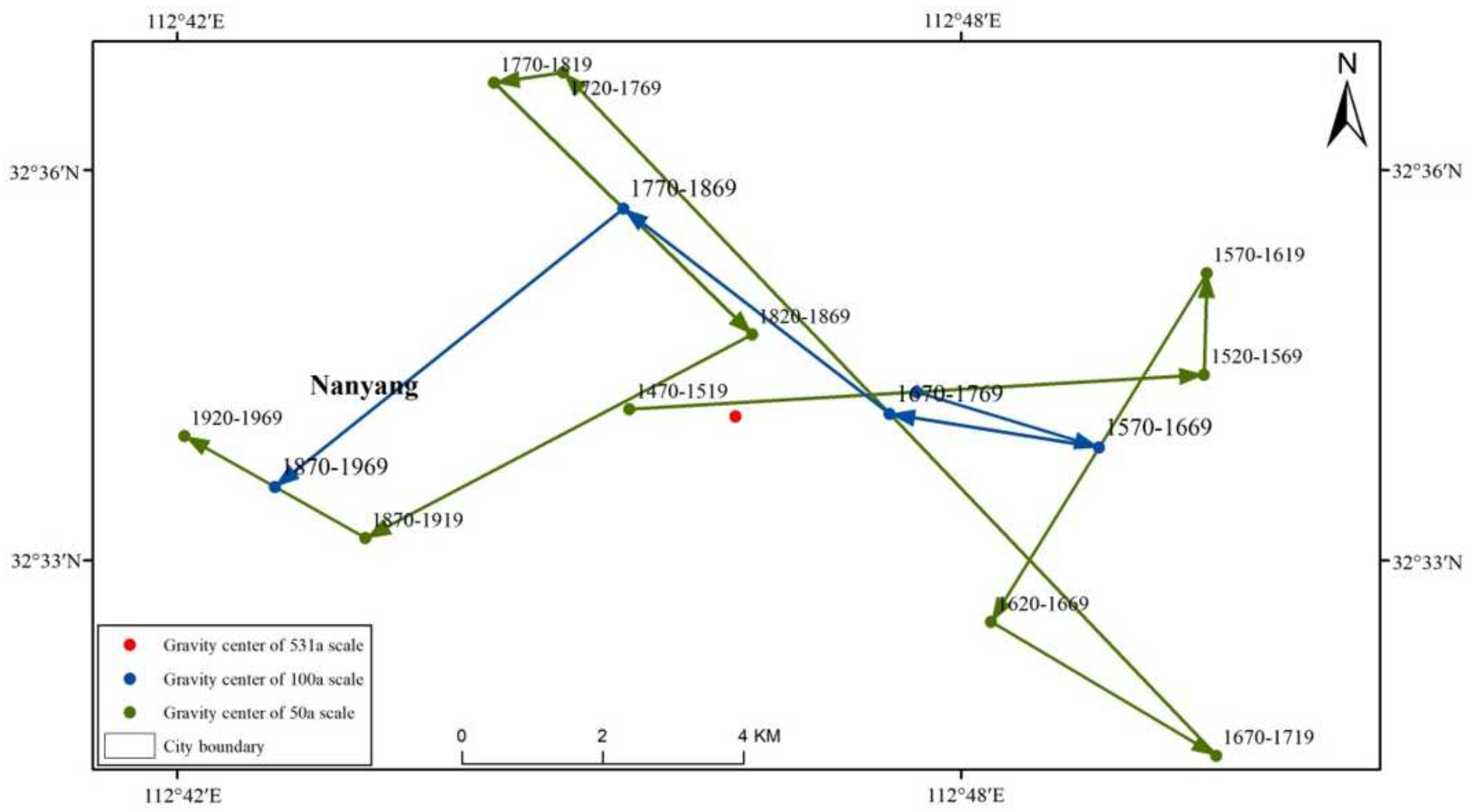

Figure 9

Migration trajectory of the drought gravity centres in different time scales. 